\title{
Chapter 8 \\ The reference accidents selected for French research reactors
}

\subsection{Definition and examples}

The reference accidents ${ }^{222}$ considered for French research reactors are accidents of internal origin (e.g. equipment failure, errors) that are considered likely to have the most severe consequences on the integrity of the fuel elements or the entire reactor core. They are very improbable in nature as they assume the occurrence of multiple failures. For some of them, reactor scram (insertion of absorber elements into the core) failure is assumed $^{223}$, or is considered ineffective given the rapidity of the accident.

The reference accidents adopted for French research reactors are primarily reactivity insertion accidents ${ }^{224}$ in the core. Others may be loss of coolant or fuel element uncovery.

222. The meaning of the expression "reference" for these accidents in (French) research reactors is different from that of the reference transients, incidents and accidents defined in the "technical guidelines for the design and construction of the next generation of nuclear power plants with pressurized water reactors" established by the GPR and German experts, and used for the EPR. These "reference" transients, incidents and accidents are broken down into four categories, depending on the estimated frequencies of the groups of events they represent; they correspond to the "operating conditions" of categories 1 to 4.

223. Transients with reactor scram failure are also known as ATWS (Anticipated Transients Without Scram) according to English terminology used for power reactors. They were studied following the Three Mile Island accident in 1979.

224. Readers are reminded that the expressions "insertion", "injection", "introduction" or "input" are used synonymously. The expression "power excursion" refers to the power transient caused by the insertion of reactivity. 
Reference accidents contribute to the very design of reactor containment, or at least verification of the design choices adopted for containment. Other external loads are taken into account for containment design or verification, including earthquakes, plane crashes, external explosions, etc. The term containment covers the third confinement barrier, consisting of the reactor building superstructures above and, depending on the configuration, below, the floor of the reactor pool or pools and underground rooms, the basemat, and the systems and equipment involved with dynamic confinement, such as ventilation systems, discharge filtration systems, etc. Other system penetrations (e.g. Systems contributing to reactor cooling) should also be taken into account. At the design phase, studies precisely define the functional requirements and technical characteristics of equipment contributing to reactor containment: thickness of concrete walls, rebar ratio, cable prestressing values, thickness of metal coatings for reactor pools, materials used, types of welds selected, ventilation rates, efficiency of filtration systems before discharge into the environment, etc.

For pool-type reactors using fuel composed of uranium and aluminium ${ }^{225}$ (OSIRIS, ORPHEE, high-flux reactor in Grenoble, JHR), a BORAX-type accident - whose main aspects will be outlined in the following sub-chapter - constitutes a reference accident. However, other reference accidents may also be studied for these reactors: clogging of water channels located between the fuel plates, a fuel element melting in air (during handling or core uncovery); these are then not reactivity accidents, but cooling accidents, resulting in fuel melt more or less quickly. Fuel melt in air accidents generally have the greatest radiological consequences (external radiation through the containment building, transfer of radionuclides into the environment); these accidents draw more on the containment capacity of the reactor building with regard to its superstructures, whereas BORAX-type accidents generally ${ }^{226}$ put more stress on the walls of the reactor pool.

For a reactor like the RHF located in the immediate vicinity of the city of Grenoble, the results of studies of reference accidents (meltdown of fuel underwater, meltdown of fuel in the air) are especially important for assessing the acceptability of the installation's design, particularly the containment building and associated systems.

The reference accidents currently ${ }^{227}$ selected for French research reactors, other than pool-type reactors, are listed briefly below.

\section{EOLE and MINERVE reactors}

For the EOLE reactor, the reference accident selected is the inadvertent lifting of a control absorber while the reactor is in operation, with supposed reactor scram failure (absorber not inserted into the core). The resulting reactivity insertion does not lead to fuel meltdown $\left(\mathrm{UO}_{2}\right)$.

225. Section 2.1 showed that all $\cup \mathrm{Al}_{x}, \mathrm{U}_{3} \mathrm{Si}_{2}$ and $\mathrm{UMo}_{\mathrm{x}}$ formula fuels also contain aluminium, added at the end of the grinding operation with the fuel powder.

226. Except for a BORAX-type accident, in the event of the possibility of a spray of water or water hammer under the reactor building dome.

227. They have changed in line with safety reviews. 
For the MINERVE reactor, the reference accident selected is reactor criticality (startup) with an abnormally constituted assembly (too powerful), loaded erroneously into the reactor core, with reactor scram failure. This leads to the insertion of $1,000 \mathrm{pcm}$ in approximately 1 second, without leading to fuel meltdown.

\section{MASURCA reactor}

For the MASURCA reactor, the reference accident selected is reactor criticality with an abnormally constituted assembly (too powerful), loaded erroneously in the largest considered core for the reactor ${ }^{228}$, with reactor scram failure. Reactivity insertion is $4.9 \$^{229}$ in 10 seconds. The facility operator had initially considered that this scenario could be excluded given the successive failures it assumes, but IRSN maintained that this was difficult to justify, given that its prevention is primarily based on provisions of an organisational nature. This type of accident does not lead to fuel meltdown, but, given the temperatures reached, the solid sodium of rodlets or platelets melts ${ }^{230}$. Given the large number of these rodlets or platelets in the reactor core, IRSN considered that it is not possible to exclude the presence of latent defects in some of their cladding. The ejection of liquid sodium from these strips would then lead to a sodium fire in contact with the core cooling air. Ultimately, the radiological (and chemical) consequences of the accident were assessed on the assumption of a fire involving $1 \%$ of the sodium present in the reactor core. The cladding of the fuel rodlets or platelets located close to the sodium strips on fire is assumed to be defective, leading to a release of radioactivity (representing approximately $4 \mathrm{TBq}$ ) into the reactor building (including fission products). Assessment of the radiological consequences of this type of accident in the environment led the French Nuclear Safety Authority (ASN) to ask the facility operator to study various provisions intended to reduce them (management of the containment building ventilation, back-up ventilation, leakages grouping, etc.) and assess the toxic risks due to sodium aerosols, particularly for operators required to perform rounds in the installation before launch of the sodium fire extinction system using argon.

\section{CABRI reactor}

The reference accident selected for the CABRI reactor is an overpower accident during operation, resulting from the simultaneous failure of four helium 3 rod pressure-relief valves (two "quick" opening valves and two "slow" opening valves - see section 5.2), with reactor scram failure, leading to an insertion of reactivity of 2,100 pcm in $20 \mathrm{~ms}$. The reactor power increases to a peak of around $25 \mathrm{GW}$, after which neutron feedback results in a rapid decline in power. Study of the scenario by the operator shows that the

228. It is possible to load different-sized cores into MASURCA.

229. For fast neutron reactors or the MASURCA mockup, which use plutonium, reference is often made to the "dollar" (\$), which corresponds to the proportion of delayed neutrons (see section 7.1 which gives some values for different types of reactors and fuels). For reactivity insertion, this is the reactivity threshold beyond which a chain reaction reaches criticality by prompt neutrons alone.

230. Sodium melts at a temperature of approximately $98^{\circ} \mathrm{C}$. 
temperature of the fuel rods increases but does not reach $\mathrm{UO}_{2}$ meltdown temperature $^{231}$ and that the mechanical criteria selected for the risk of cladding failure are not reached during the transient.

\subsection{BORAX-type accident - main aspects}

The BORAX-type accident has been selected in France as the reference accident for pool-type research reactors using uranium- and aluminium-based metal fuel in the form of plates (cores), contained between two thin aluminium sheets, which serve as cladding. For this type of fuel, meltdown begins with aluminium at $660{ }^{\circ} \mathrm{C}$.

The 1961 accident in American reactor SL-1 (Stationary Low Power Reactor Number One) and experiments conducted in the USA in the 1950s and 1960s demonstrated that in the event of a sudden and significant input of reactivity, these types of reactors may be subject to explosive phenomena resulting from the degradation or fast meltdown of part of the reactor core. Since then, this type of accident has been called a BORAX-type accident, named after the (five) reactors of the same name at the ANL (Argonne National Laboratory) in the state of Idaho (National Reactor Testing Station), which were used to conduct experiments into this type of accident.

The circumstances surrounding the accident on Reactor SL-1 are summarised briefly below, with the lessons learned. The phenomena involved in this type of accident and the way in which they are taken into account for the design of pool-type research reactors ${ }^{232}$ will then be explained.

\subsubsection{Accident at the SL-1 reactor}

The SL-1 reactor was a US Army experimental reactor built at the the Idaho National Laboratory (INL) site, approximately $65 \mathrm{~km}$ west of Idaho Falls, as part of a programme seeking to develop power reactors to supply electricity to remote sites, such as surveillance radar stations. It was commissioned on 11 August 1958. The reactor's maximum thermal power was $3 \mathrm{MW}$ and it was capable of electricity output of $200 \mathrm{~kW}$. The reactor core consisted of approximately one hundred uranium- and aluminiumbased plates, with aluminium cladding, and grouped into fuel assemblies; the fuel was manufactured at the Argonne National Laboratory. The uranium was enriched to $93 \%$ in isotope 235 . The reactor had nine cadmium-based absorber rods. The water in the (closed) reactor vessel served both as coolant and moderator.

In late December 1960, the decision was taken to perform maintenance on the absorber rods following various jamming incidents affecting these rods. The reactor was shut down to carry out this maintenance; the rods were placed in the low position and disconnected from their control mechanisms.

231. It will be seen in section 10.1.1 that slow ramps were in fact more damageable for the fuel that pulses, that was not identified, but there will be no more slow ramps in CABRI.

232. For more detail, please consult the following document drawn up by IRSN in 2011: Consideration of BORAX-type reactivity accidents applied to research reactors, Reference documents series, IRSN 2010/128, available at https://www.irsn.fr/EN/Pages/home.aspx. 
On the afternoon of 3 January 1961, after maintenance operations had been completed, a team reconnected the mechanisms to their respective rods in order to restart the reactor.

At $9 \mathrm{pm}$, alarm signals from the reactor building sounded at three fire stations. These alarms did not make it clear whether the problem was a fire or an abnormal radiation level. Upon their arrival on site, the emergency response teams could not detect any visible signs of damage or fire. However, very high dose rates were detected at the entrance to the reactor building, with values of around 1,000 rad/hour (10 Gy/h) in the reactor hall. Two people were found motionless near the reactor, while the third had been projected and pinned to the ceiling of the building by one of the absorber rods. Two of the three men were killed instantaneously, while the third died two hours after the accident, while being transferred to hospital.

The inspections performed with the support of a robot concluded that only the central absorber rod had been ejected. The other absorber rods had remained inside the core, which had suffered major radial deformation. A radiation shielding plug had been ejected onto the ceiling of the building. The state of the core can be seen in figure 8.1. The vessel and the reactor building both withstood the accident.

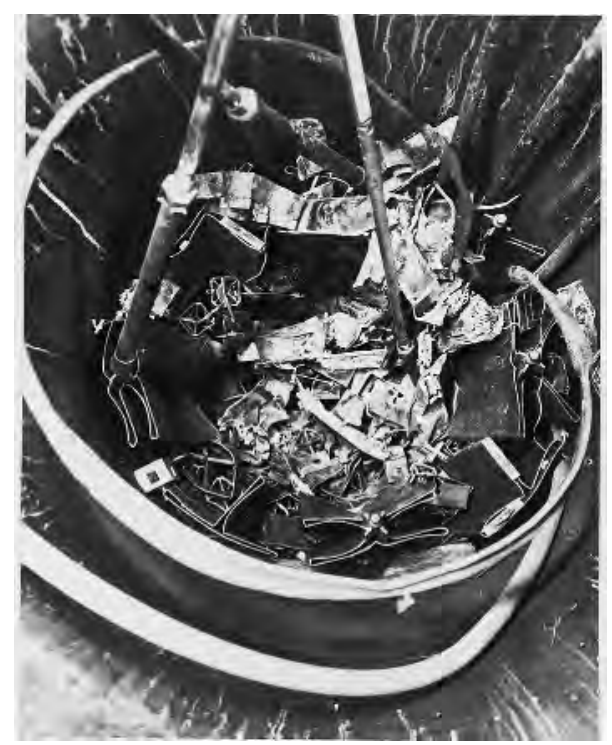

Figure 8.1. View of the SL-1 reactor core after the reactivity accident in 1961, three of the rod mechanisms are visible. @ INL.

The most widely-accepted theory to explain the accident is that an absorber rod got stuck and one of the operators decided to free it manually, but withdrew it too far. The rod was raised too high, exceeding the limit above which chain reaction runaway becomes uncontrollable, thus leading to the reactor explosion. Mainly due to the presence of a short-lived yttrium isotope found on the dead operators' clothing, it has been estimated 
that the reactor power may have surged to around 20,000 MW during the accident ${ }^{233}$. Given the damage observed, it was estimated that the vessel pressure exceeded 30 bars.

It took over a year to decontaminate the SL-1 reactor building. All debris from the reactor was fully removed and the building was demolished in 1962.

The most exposed members of the rescue crew received an estimated dose of 30 rad (0.3 Gy). There were no significant radiological consequences outside the building, which contained almost all (99.99\%) of the radioactivity (figure 8.2). Downwind of the SL-1 reactor, the radiological impact on plants remained low and no groundwater contamination was detected.

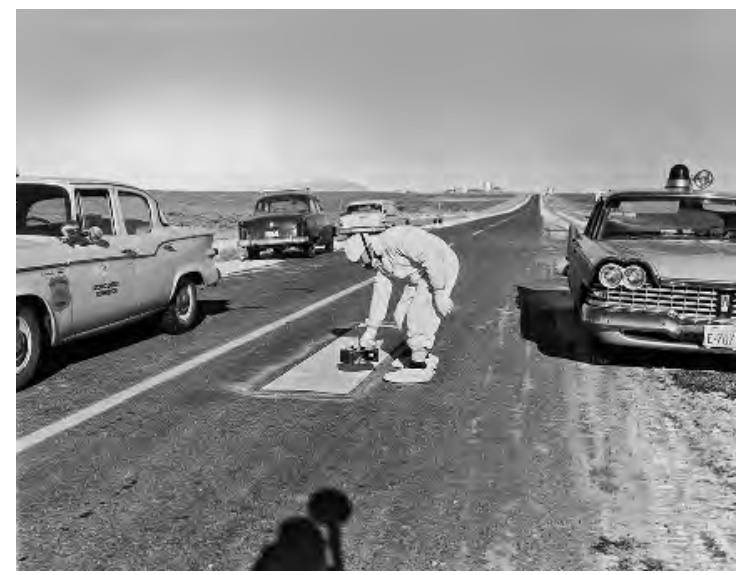

Figure 8.2. Measurement of ground contamination near Reactor SL-1. @ INL.

The data available regarding this accident shows that, in addition to ensuring radiological protection of crews, one of the main concerns of the people in charge of organising the emergency response was to avoid any risk of a second nuclear accident, by ensuring that there were enough absorber rods in the reactor core and that there was no danger of the ejected plug falling back down on top of the reactor.

\subsubsection{Key lessons learned from the SL-1 reactor accident}

The accident that occurred in the SL-1 reactor, together with tests carried out in the USA in 1954 in the BORAX-1 reactor and then in 1962 in the SPERT-1 reactor (see table 8.1 at the end of this chapter) showed that in the event of a sudden and significant input of reactivity, water-cooled research reactors that use uranium- and aluminiumbased fuel may be subject to the following two explosive mechanisms resulting from

233. With a total of $1.5 \times 10^{18}$ fission reactions. 
the degradation or fast meltdown of part of the reactor core (the two mechanisms could potentially co-exist):

- sudden water vaporisation (steam explosion),

- sudden aluminium vaporisation.

These phenomena can result in the creation of shock waves and the expansion of bubbles in the reactor coolant, and for pool-type reactors, in the pool. These bubbles may contain non-condensable gases (e.g. hydrogen resulting from the oxidation of aluminium or experimental devices), which could amplify the mechanical effects of the expansion of steam bubbles - leading to a mechanical "impulse ${ }^{234 "}$ on structures.

This type of accident may lead to:

- significant damage to the reactor block, reactor coolant system and reactor pool walls;

- damage to the lower part of the containment (bottom of the reactor pool), due to the thermal effects of the molten materials accumulating there;

- water transfer into the reactor building due to a steam explosion, which may impact the reactor building ceiling ("water hammer" effect) before falling back into the reactor pool. Part of this water transferred into the reactor building may be projected in the form of a water spray;

- an increase in atmospheric pressure and temperature in the reactor building, particularly due to thermal exchanges with the water spray, volatile fission products and noble gases released into the building, and potentially any fuel fragments or particles released;

- very high dose rates inside the reactor building and potentially outside;

- radioactive discharge into the environment.

\subsubsection{Consideration of the BORAX-type accident in France}

\subsubsection{General considerations}

In France, the possibility of a BORAX-type accident has systematically been taken into account in containment design for water-cooled research reactors operated using uranium- and aluminium-based fuel.

Consideration of this type of accident includes:

- definition of the provisions intended to make it highly improbable, considering all possible initiating events of an insertion of reactivity into the reactor core;

- determination of an envelope accident to define the potential consequences within the installation itself;

234. Characterised by a pressure time profile, with the peak value and duration. 

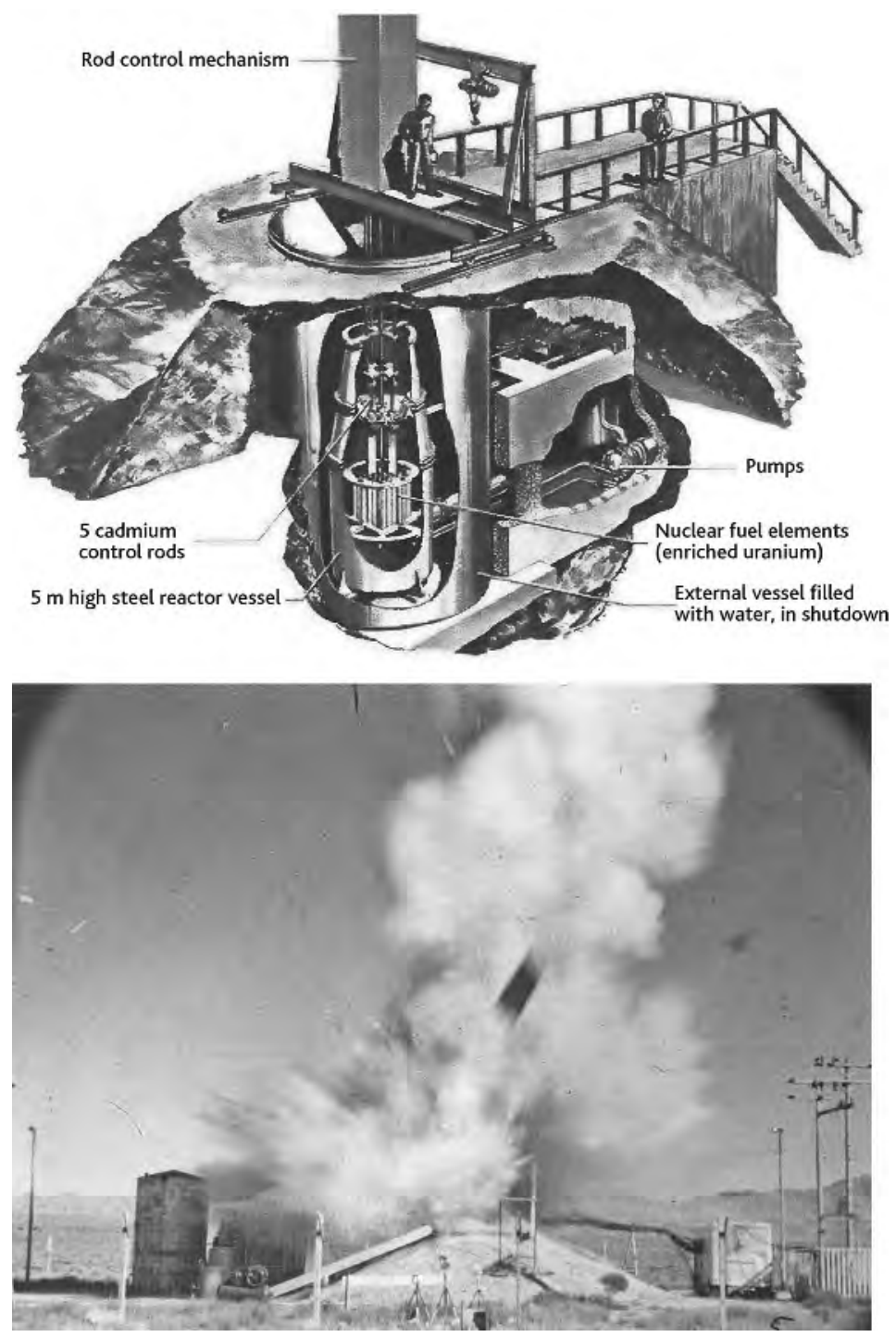

Figure 8.3. Top, diagram of the BORAX-1 reactor. ( $)$ All rights reserved. Bottom, photograph taken during the final destructive testing of the BORAX-1 reactor. () Argonne National Laboratory (creative commons).

- assessment of these consequences in order to check compliance with the necessary functional requirements in such a situation for the different equipment items that contribute to maintaining the core underwater (after the initial phase during which a spray of water may be produced) and containment (reactor building, liners and pools, ventilation and filtration systems, and post-accident cooling systems, etc.). 
In order to ensure robust reactor containment in the event of a BORAX-type accident, the characteristics selected for this accident must be sufficiently conservative or fall under an envelope approach.

Examples of the initiating events considered are the ejection of one or more absorbers elements and reactivity insertion associated with the inadvertent removal of an experimental absorbing device.

Consideration of a BORAX-type accident in the design of pool-type research reactors operated using uranium- and aluminium-based fuel remains necessary when a reactivity accident is possible. In this respect, it should be noted that:

- the reactors in question are installations whose purposes require them to offer a variety of uses so that they can be used to carry out experimental programmes, produce radioisotopes, etc., often at the same time. Many operations can be performed in the reactor core or nearby;

- these reactors can undergo changes in their purposes or equipment over time. The chosen experiments may require the installation of dedicated support systems, which may create risks that were not explicitly considered during initial reactor design (e.g. use of pressurised gas). Consideration of a BORAX-type envelope accident at the initial design stage makes it easier to implement such changes at a later date;

- these reactors may use specific equipment for which there is no reliable data or very little operating feedback;

- for some of these reactors, organisational and human factors can have particular importance for the prevention of incidents and accidents. Although lessons were learned from the Reactor SL-1 accident and major accidents affecting power reactors (particularly Three Mile Island and Chernobyl), the possibility of human error remains and the chances of recovering from such errors are difficult to assess. More generally, it is difficult to determine the robustness of organisational lines of defence. Finally, as stated in section 7.2.3, the co-existence of two types of personnel in the installation (facility operators and scientists), each with their own objectives, creates a complex situation, particularly during experimental phases where both types of personnel are in constant interaction.

\subsubsection{Key aspects and parameters}

A certain number of aspects and parameters associated with a BORAX-type accident are of prime importance in the design of a pool-type reactor operated using uraniumand aluminium-based fuel:

- determination of the thermal energy "deposited" in the reactor core, which is intended to form an envelope for potential reactivity accidents in this reactor;

- conditions for triggering a steam explosion by heat transfer between the molten fuel and water;

- assessment of the potential resulting pressure; 
- assessment of thermomechanical loads (shock waves, water thrust associated with the expansion of bubbles, etc.) on structures contributing to containment (including the pool), and any potential resulting damage;

- post-accident cooling of molten materials that may flow to the bottom of the pool or into the lower parts of the reactor building through singularities (absorber mechanism penetrations, etc.);

- the risks of a second reactivity accident ("recriticality" or "return to criticality"), particularly by (molten or solid) fuel shuffling;

- the corresponding radiological consequences following the transfer of radionuclides from the core into the building housing it, and then from said building into the environment.

As for core meltdown accidents in pressurised water reactors, it is complex to characterise and quantify the various consequences of a BORAX-type accident due to the large number of simultaneous equipment geometry phenomena (reactor core tank or vessel, reactor coolant system, reflector, experimental systems, pool liner, pool concrete walls, etc.). Therefore, in order to determine the validity of the fundamental assumptions adopted for the design of elements that contribute to the confinement of radioactive substances, during the design phase of a new reactor, one approach is to use specific assessment tools - using sufficiently conservative assumptions - for each of the effects of the accident, each considered separately (shock waves and expansion of bubbles on the side walls of the pool, "water hammer" and water spray on the top part, radiological consequences in the environment, etc.), in order to estimate these effects with sufficient margins.

Some effects may not be taken into account, for example a spray of water or "water hammer" under the ceiling of the reactor building, if based on representative experiments.

For this publication, only two important aspects of a BORAX-type accident will be developed: the "deposition" of thermal energy in the reactor core and the steam explosion, by stating the main points of concern for each aspect.

\section{The notion of energy deposition in the reactor core}

The power transient resulting from the insertion of reactivity in a reactor core can be characterised by various parameters: maximum power reached, transient duration until return to initial conditions, or the total power integrated for this duration, which corresponds to what is generally referred to as the (thermal) energy deposited in the reactor core. This final parameter is especially important in design studies for a research reactor where the possibility of a BORAX-type accident is considered, as it largely determines the scale of the potential resulting steam explosion, and therefore the consequences for the reactor and especially the elements contributing to its containment.

It should be noted that for the last research reactors built in France in the $20^{\text {th }}$ century, i.e. the RHF at Grenoble and then the ORPHEE reactor at Saclay, an "inclusive" approach was adopted: an energy deposition of $135 \mathrm{MJ}$ was selected, which corresponds 
to meltdown of the entire reactor core, which is assumed to reach a temperature of around $800{ }^{\circ} \mathrm{C}$ during the reactivity transient. At the time of the design of these reactors, these values were considered to offer reasonable envelope values, on the basis of lessons learned from the SL-1 reactor accident and tests carried out on the BORAX-1 and SPERT-1 reactors.

The thermal energy must be calculated on the basis of the reactor specifics, in particular the quantity of fuel in its core, especially considering that experimental data for a BORAX-type accident, which is mainly taken from feedback from the Reactor SL-1 accident and tests conducted in the BORAX-1 and SPERT-1 reactors, does not demonstrate any phenomena that should limit energy deposition in the reactor core during the accident at a generic value, independent of the reactor characteristics. Energy deposition is heavily dependent on the reactivity inserted, the kinetics by which it is inserted, neutron feedback and the quantity of fuel in the reactor core. The energy value adopted in the end must be an envelope value that offers sufficient margins to ensure the robustness of reactor containment under the various potential reactivity insertion scenarios, which of course must take in to account the provisions adopted for reactivity control (substantiated by tests where necessary).

It should also be noted that the oxidation of aluminium in the reactor core during the accident may lead to a very high increase in thermal energy in the pool water, which could modify the scale of the steam explosion. This is also true for the potential exothermic destruction of "heat sinks" and "heat sources".

\section{Steam explosions}

A steam explosion is assumed in reports on the destructive tests carried out in the BORAX-1 and SPERT- 1 reactors and the Reactor SL-1 accident.

A steam explosion can occur through contact between two liquids, between the molten fuel, which is extremely hot, and the coolant, which is cold and volatile. This is an interaction of a thermodynamic nature, with complex trigger conditions. It leads to the fragmentation and solidification of the molten materials and the vaporisation of the cold liquid.

The scale of a steam explosion depends on multiple parameters, in particular:

- the total quantity of energy potentially mobilized: the thermal energy deposited, as mentioned above (fraction of molten core and its temperature), in addition to the energy contributed by the oxidation of aluminium and any energy released through the destruction of experimental systems, in particular "hot sources" and "cold sources";

- the duration of thermal exchanges between the molten materials and water.

Although the experimental observations demonstrate that an explosive thermodynamic interaction between molten fuel and the coolant does not occur systematically, it remains necessary to consider the possibility of such an interaction when molten materials come into contact with coolant in liquid state. 
The steam explosion may lead to the propagation of shock waves and the movement of masses of water by the surge of the steam bubble expanding. These phenomena may lead to:

- deformation or failure of structures and equipment: metal casing surrounding the reactor core, the upper core plate and reactor coolant piping, experimental systems located around the core, equipment in the pool, the reactor pool liner, sluice gate (cofferdam) between the pool and a transfer channel, etc.;

- the ejection of a mass of water in the reactor building, potentially with a "water hammer" effect on the building dome.

Special attention must be paid to the potential mechanical effects of thermodynamic interactions between the molten materials and water for each reactor studied, depending on factors such as the hydrostatic pressure of the water in the reactor core pool (water level above the core), the volumes and inertia of masses of water liable to be moved, the stiffness and inertia of internal metal structures and the pool liner, etc. In this respect, the stiffness of the "environment" around the interaction zone may differ depending on the direction. For example, water movement in an upwards direction would be preferential.

The shock waves produced by the steam explosion cause pressure spikes on the pool walls, which can reach extremely high levels of several dozen bars, but for very short durations (around $10 \mathrm{~ms}$ ). The expansion of the steam bubble generates a longer-lasting pulse. These two types of mechanical loads need to be studied on a case-bycase basis, without excluding either of them, depending on the characteristics (inertia, stiffness, etc.) of the elements comprising the pool of the reactor being considered (very thick concrete walls, thin metal liner, whether or not it is attached to the concrete walls, etc.).

Protection of the pool walls and bottom may be strengthened:

- by leaving an empty space between the liner or reactor vessel and the pool walls axially to the core. This provision enables mechanical energy to be absorbed by deformation of the liner or vessel, which reduces stresses on the pool structure (provision adopted for the SILOE, ORPHEE and JHR reactors);

- by installing deformation-based energy absorption mechanisms, e.g. metal plates on "resilient bearing pads" at the bottom of the pool (as adopted for the SILOE reactor). For the Jules Horowitz reactor, a metal plate is placed on the ceiling of the absorber mechanisms vault; measures ("provisions") have also been taken to install shock absorbers (honeycomb structure type) in the reactor pool to protect its side walls.

\subsection{Demonstrative testing conducted in France}

The quest for a robust research reactor design with regard to reference accidents may lead to the use of various types of testing in addition to assessments carried out using numerical simulations. This is especially true where inherent limitations in 
the simulation and tools used appear, for example, when it is impossible to correctly model structure singularities. But this generally raises delicate questions regarding the similitude 235 sought and the representativity of testing.

These kinds of tests were carried out for French research reactors, for various aspects related to reference accidents (see table 8.2 at the end of this chapter), focusing on:

- for the high-flux reactor in Grenoble, specifying the variation kinetics in the core reactivity in the event of switching from light water to heavy water in the core: tests were carried out on the reactor itself using heavy water mixed with light water at various concentrations;

- for the Jules Horowitz reactor, determining, with a mockup, the speed at which an absorber is raised in the event of accidental ejection due to failure of the control mechanism;

- for the ORPHEE reactor, ensuring, with the use of in-basin testing ${ }^{236}$, proper pool resistance at the horizontal neutron channel penetrations (pool liner by the channel penetrations, safety "windows" and valves on the thimbles - see section 7.3.2) in order to ensure that the core would not be uncovered due to loss of neutron channel watertightness in the event of a BORAX-type accident. The tests involved subjecting the abovementioned equipment (on models at a scale of $1 / 10$ for liner resistance tests and 1/2 for channel watertightness mechanisms) to a water pressure wave (from an "air canon" or rapid expansion of a volume of compressed air), representative of a BORAX accident - expansion of a steam bubble initially at 40 bars with a volume of $4 \mathrm{~m}^{3}$;

- checking the overall behaviour of structures in the event of a BORAX-type accident. For example, a test was conducted using an explosive (TNT) on a $1 / 3$ scale model of the OSIRIS reactor (table 8.2 ).

235. Various similitudes are possible: structure deformation, structure displacement, etc.

236. Carried out by SODERA (Société pour le développement de la recherche appliquée) in its laboratories. 
Table 8.1. Some characteristics and observations concerning the SL-1 reactor accident and power excursion tests conducted in the SPERT and BORAX reactors.

\begin{tabular}{|c|c|c|c|c|c|c|c|c|c|}
\hline Reactor & Description & $\begin{array}{c}\text { Total } \\
\text { mass of } \\
\mathrm{Al} / \mathrm{U}(\mathrm{kg})\end{array}$ & $\begin{array}{c}\text { Reactivity } \\
\text { inserted } \\
(\$)^{3}\end{array}$ & $\begin{array}{c}\text { Power } \\
\text { spike (MW) }\end{array}$ & $\begin{array}{l}\text { Thermal } \\
\text { energy } \\
\text { deposited } \\
\text { (MJ) }\end{array}$ & $\begin{array}{c}\text { Chemical } \\
\text { energy released } \\
\text { (MJ) }\end{array}$ & $\begin{array}{c}\text { Max. fuel } \\
\text { temperature } \\
\left({ }^{\circ} \mathrm{C}\right)\end{array}$ & $\begin{array}{l}\text { Pressure } \\
\text { spike (bar) }\end{array}$ & $\begin{array}{l}\text { Damage } \\
\text { observed to } \\
\text { reactor core }\end{array}$ \\
\hline BORAX-I & $\begin{array}{l}\text { Destructive } \\
\text { test }\end{array}$ & $100 / 4.2$ & 3.1 & $<19,000$ & 135 & Undetermined & $<1,800$ & $400-700$ & $\begin{array}{l}\text { Extensive core } \\
\text { meltdown }\end{array}$ \\
\hline SL-1 & Accident & 189/14 & 3.0 & $\sim 19,000$ & $133 \pm 10$ & $24 \pm 10$ & $>2,075$ & 700 & $\begin{array}{c}\sim 20 \% \text { of core } \\
\text { melted } \\
\sim 2 \% \text { of core } \\
\text { vaporised }\end{array}$ \\
\hline \multirow[t]{2}{*}{ SPERT-I } & $\begin{array}{c}2 \text { final non- } \\
\text { destructive tests }\end{array}$ & $51 / 3.8$ & $\begin{array}{l}2.6 \\
2.7\end{array}$ & $\begin{array}{l}1,130 \\
1,270\end{array}$ & $\begin{array}{l}11 \\
19\end{array}$ & - & $\begin{array}{l}585 \\
680\end{array}$ & $\begin{array}{l}0.5 \\
0.5\end{array}$ & $\begin{array}{c}\sim 0,5 \% \\
\text { of core melted } \\
\sim 2 \% \text { of core } \\
\text { melted }\end{array}$ \\
\hline & $\begin{array}{l}\text { Destructive } \\
\text { test }\end{array}$ & & 3.55 & 2,250 & 31 & 3.5 & 1,360 & $<300$ & $\begin{array}{c}-35 \% \text { of core } \\
\text { melted }\end{array}$ \\
\hline
\end{tabular}


Table 8.2. Simulation testing on models of a BORAX-type accident for French research reactors.

\begin{tabular}{|c|c|c|c|c|c|}
\hline \multirow[t]{2}{*}{ Reactor } & \multirow[t]{2}{*}{$\begin{array}{c}\text { Operating } \\
\text { power }\end{array}$} & \multicolumn{2}{|c|}{$\begin{array}{c}\text { Structure } \\
\text { characteristics }\end{array}$} & \multirow[t]{2}{*}{$\begin{array}{l}\text { Model } \\
\text { scale }\end{array}$} & \multirow[t]{2}{*}{$\begin{array}{l}\text { Structures } \\
\text { studied }\end{array}$} \\
\hline & & Pool & Reactor building & & \\
\hline TRITON & $6 \mathrm{MW}$ & $\begin{array}{l}\text { Prestressed } \\
\text { concrete }\end{array}$ & $\begin{array}{l}\text { Concrete building } \\
\text { with glass windows }\end{array}$ & $1 / 5$ & $\begin{array}{l}\text { Pool and effect of } \\
\text { the spray of water } \\
\text { on the building }\end{array}$ \\
\hline MELUSINE & $8 \mathrm{MW}$ & $\begin{array}{c}\text { Prestressed } \\
\text { concrete, with } \\
\text { steel } \\
\text { liner in the } \\
\text { compartment } \\
\text { containing the } \\
\text { core }\end{array}$ & $\begin{array}{c}\text { Concrete building } \\
\text { with observation ports }\end{array}$ & $1 / 3$ & $\begin{array}{l}\text { Pool and neutron } \\
\text { channels }\end{array}$ \\
\hline SILOETTE & $100 \mathrm{~kW}$ & $\begin{array}{l}\text { Steel vessel } \\
\text { contained in } \\
\text { ordinary solid } \\
\text { concrete }\end{array}$ & $\begin{array}{c}\text { Metal } \\
\text { containment }\end{array}$ & $1 / 3$ & $\begin{array}{l}\text { Pool and neutron } \\
\text { channels }\end{array}$ \\
\hline OSIRIS & $50 \mathrm{MW}$ & $\begin{array}{l}\text { Reinforced } \\
\text { concrete with } \\
\text { steel liner }\end{array}$ & $\begin{array}{c}\text { Concrete building } \\
\text { with observation ports }\end{array}$ & $1 / 3$ & $\begin{array}{c}\text { Pool, core support } \\
\text { structure and effect } \\
\text { of the spray of water on } \\
\text { the building }\end{array}$ \\
\hline
\end{tabular}


